\title{
Oligosymptomatic neuroendocrine neoplasm of the small intestine with metastases spread to the heart, bones, muscles and intraperitoneally after a few years in remission - diagnostic and therapeutic challenges
}

\author{
Natalia Tyrybon, Agnieszka Żyłka, Joanna Długosińska, Małgorzata Benke, Marek Dedecjus
}

\begin{abstract}
A fifty-one-year-old male patient with a history of recurring abdominal pains and signs of subileus, without carcinoid syndrome signs, underwent a laparatomy with a resection of the small intestine segment. Histopathology revealed a well-differentiated neuroendocrine neoplasm of the small intestine. Due to the lack of hormonal activity and low malignancy potential the patient was not qualified for adjuvant therapy. The yearly computed tomography did not indicate a recurrence of the neoplasm. The patient did not report any "red flag" symptoms. After a few years in remission [ $\left.{ }^{68} \mathrm{Ga}\right]-D O T A T A T E$ PET/CT revealed a dynamic development of the illness. The patient was qualified for palliative treatment with long-acting somatostatin analogue. Due to the treatment's ineffectiveness and further progression of the disease, the patient received Peptide Receptor Radionuclide Therapy (PRRT). In spite of the therapy his condition did not improve and progression was observed. The patient died because of a malfunction of the cardiac conduction system caused by metastases in the heart.
\end{abstract}

Key words: neuroendocrine neoplasm, carcinoid syndrome, somatostatin analogue, radioisotope therapy

\section{Introduction}

Gastro-entero-pancreatic neuroendocrine neoplasms (GEP-NENs) form a diverse group of neoplasms arising from the cells of the diffused endocrine system in the gastrointestinal tract. Although they are usually benign and develop slowly, they can present a whole spectrum of malignancy and become resistant to therapy. They make up to $70 \%$ of the neuroendocrine neoplasm (NENs) group and are most often found in the small intestine, rectum, appendix and large intestine $[1,2]$. The prevalence rate is about 35 cases per 100000 and they can occur at any age, but peak incidence is usually in the sixth decade of life [1]. Clinical classification is based on the tumours' ability to secrete hormones. Nonsecreting ones cause a variety of nonspecific symptoms, usually associated with mass effect. Active ones are able to secrete various substances, depending on which cells they arise from. The mentioned substances are responsible for characteristic symptoms. In the case of the small intestine NENs, the most often secreted substance is serotonin, which can cause carcinoid syndrome. This syndrome occurs in approximately $40 \%$ of patients with small intestine NENs and is associated with rapid flushing of the face and the

\section{How to cite:}

Tyrybon N, Żyłka A, Długosińska J, Benke M, Dedecjus M. Oligosymptomatic neuroendocrine neoplasm of the small intestine with metastases spread to the heart, bones, muscles and intraperitoneally after a few years in remission - diagnostic and therapeutic challenges. NOWOTWORY J OnCO/ 2020; 71: 111-114. 
upper torso, diarrhoea, abdominal pain, teleangiectasia and bronchoconstriction [3]. In 50\% of cases the syndrome is accompanied by damaged heart valves induced by increased exposure to to serotonin (Hedinger syndrome), which may result in right-sided heart failure - the most common death cause among people suffering from carcinoid syndrome [4].

\section{Case report}

A fifty-one-year-old male patient with a history of recurring abdominal pains was admitted to the surgery department on February 2011 due to the suspicion of subileus. An ultrasound examination (US) showed partial dilatation (up to $40 \mathrm{~mm}$ ) of the small intestine, with a colonoscopy revealing polyps and multiple diverticula in the descending colon. An X-ray of the digestive tract suggested advanced subileus. The patient was qualified to laparotomy and during surgery a part of the narrowed ileum with tumour was resected. Histopathology revealed well-differentiated NEN in submucosal localisation, invading the muscular layer of the intestinal wall, without lymph node involvement (NEN G1 pT2N0). The patient was referred to the M. Sklodowska-Curie National Research Institute of Oncology in Warsaw. Due to the early stage of the disease, lack of hormonal activity of the tumour, the patient was not qualified for adjuvant therapy, and, instead, regular imaging tests were ordered. In the abdominal CT with contrast, performed annually during follow-ups, the patient did not show any alarming symptoms. After 5 years of asymptomatic course of the disease, an abdominal CT from August 2016 revealed lymph node package with desmoplastic reaction, located anteriorly to the aortic bifurcation, in the adipose tissue of the mesentery. After 3 months the patient was hospitalised due to abdominal pain - ileus was ruled out. A CT showed possible recurrence of the neoplastic process. In February 2017 [ ${ }^{68} \mathrm{Ga}$ ]-DOTATATE PET/CT was performed and it revealed multiple metastases and increased expression of somatostatin receptors in the heart, skeleton, muscles, mesentery and intraperitoneally (fig. 1, fig. 2).

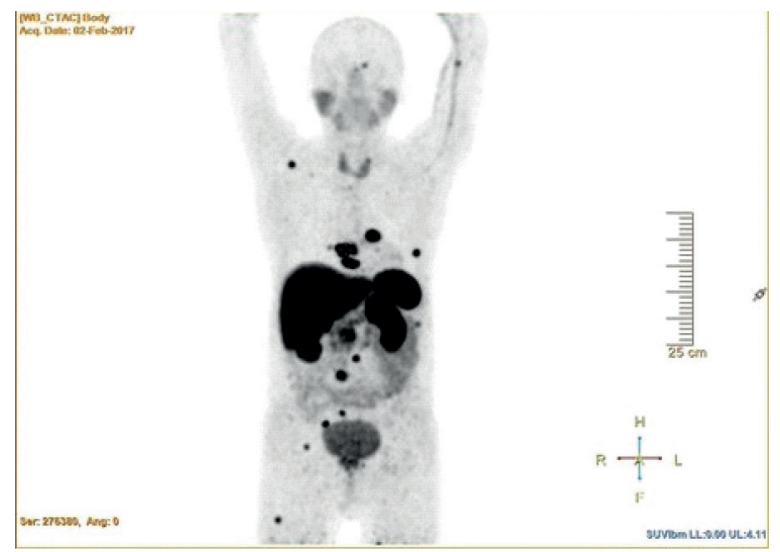

Figure 1. $\left[{ }^{68} \mathrm{Ga}\right]$-DOTATATE PET/CT before treatment with long-acting somatostatin analogues: numerous metastases, multiple localisations with increased expression of SST receptors in heart, skeleton, muscles, mesentery and intraperitoneally

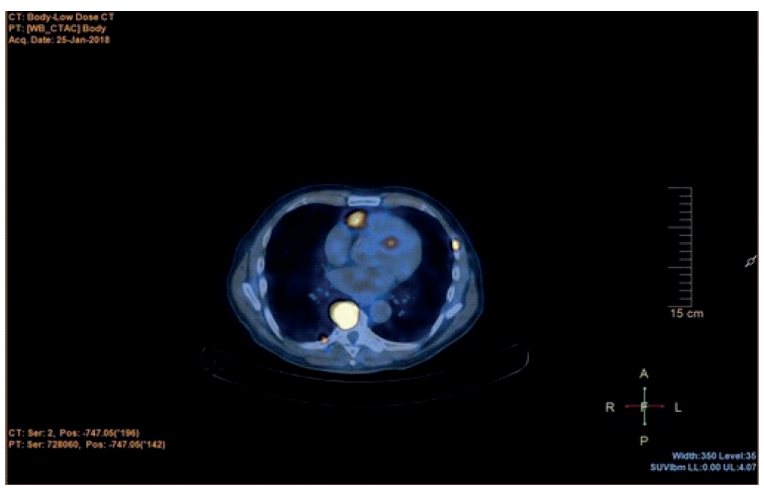

Figure 2. $\left[{ }^{68} \mathrm{Ga}\right]$-DOTATATE PET/CT before treatment with long-acting somatostatin analogues: pathological concentration of SST receptors in the area next to the pulmonary trunk, right heart ventricle and in the spine

The patient was qualified for palliative treatment with long-acting somatostatin analogue - octreotide - (Sandostatin LAR), which was administered once each 28 days subcutaneously with a dosage of $30 \mathrm{mg}$. The treatment was well tolerated, 12 cycles overall were administered. Control $\left.{ }^{68} \mathrm{Ga}\right]-D O T A T A T E$ PET/CT performed after one year showed progression of the disease, including an increase in the number of metastases and SST receptors (fig. 3). Due to the concurrent increase in CgA levels $\left(91,87 \mathrm{ng} / \mathrm{ml}-6^{\text {th }}\right.$ cycle, $162,9 \mathrm{ng} / \mathrm{ml}-12^{\text {th }}$ cycle) the treatment with Sandostatin LAR was terminated and the patient was qualified for peptide receptor radionuclide therapy with radiolabelled somatostatin analogues (PRRT). In July 2017 [177Lu]-DOTATATE 3,7 GBq treatment was started, post-therapeutic scintigraphy revealed pathological accumulation of the marker in multiple locations with a CgA level of 523,1 ng/ml. The same treatment was repeated in October 2018, but the disease showed no sign of regression and $\mathrm{CgA}$ levels remained high (443,9 ng/ml) (fig. 4). A thoracic CT showed intrapericardial tumours near the pulmonary trunk $(34 \times 34 \mathrm{~mm})$, in the right ventricle $(26 \times 20 \mathrm{~mm})$ and on the border between the right atrium and the right ventricle $(32,5 \times 20 \mathrm{~mm})$ (fig. 5).

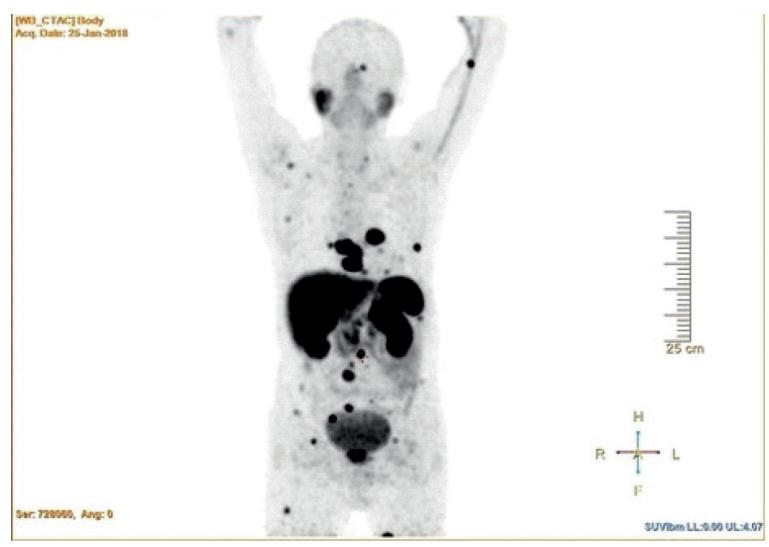

Figure 3. $\left[{ }^{68} \mathrm{Ga}\right]$-DOTATATE PET/CT after 12 cycles of treatment with long-acting somatostatine analogues - progression of the disease, new metastases 


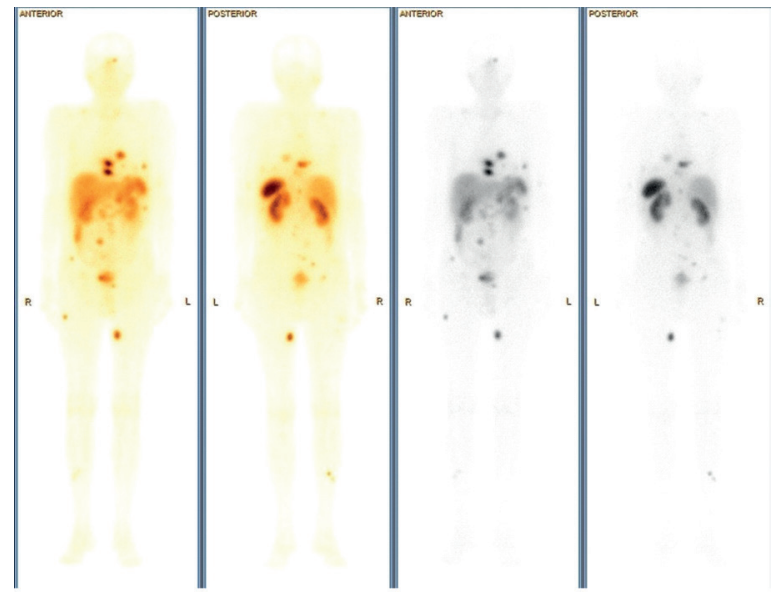

Figure 4. Post-therapeutic scintigraphy after [ ${ }^{177}$ Lu]-DOTATATE treatment: pathological accumulation of the marker in the left paranasa region, near both sternoclavicular joints, in the right scapula, along the axis of the thoracic spine, in the right iliac bone, left pubic bone, sacral bone, right femur bone, on the left side of the thorax, left side of the abdomen and medially on the proximal end of the thigh

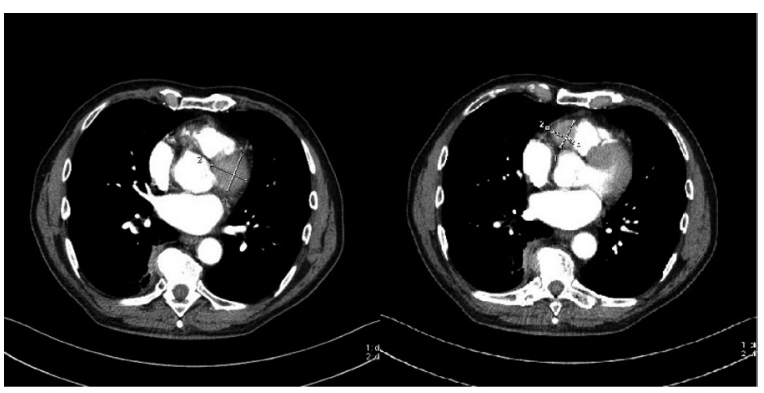

Figure 5. Thorax CT with contrast after 2 cycles of radionuclide therapy: intrapericardial tumours near pulmonary trunk and in the right ventricle

Metastases were found in the spleen and epigastric peritoneum. Fibrous scarring was present in both lungs, sternal manubrium and Th9 and Th10 vertebral bodies. An echocardiography $(\mathrm{ECHO})$ revealed a pathological mass in the heart wall, on the border of the right ventricle wall and the right atrium, with possible right fibrous ring infiltration. The patient did not show any signs or symptoms of carcinoid heart disease. He died two months afterwards due to cardiological complications after the electrical conduction system was infiltrated.

\section{Discussion}

In most patients, small intestine NENs are well-differentiated and grow slowly [5]. Hormonally inactive NENs are associated with a variety of localised symptoms. Patients usually report chronic, non-specific abdominal pain, which can suggest some other functional disorders and therefore delay the actual diagnosis [6]. This particular case relates to a small intestine NEN of G1, showing no hormonal activity and causing no carcinoid syndrome, manifesting itself only as intermittent subileus.

The desmoplastic reaction, which could be observed in the patient's mesentery, is typical in NETs and could exacerbate the pain by impairing intestinal blood circulation.
This reaction is associated with a more advanced grade of disease and poorer prognosis [7, 8]. Patient did not report any "red flag" symptoms and did not present typical carcinoid syndrome, even during progression, which suggested a stabilisation of the illness. The asymptomatic course of the disease played a major role in withdrawing from measuring the plasma chromogranin A concentration, a prognostic factor that allows for monitoring the course of the illness $[8,9]$. According to the Polish Endocrine Society standards, when looking for a primary tumour site and grade, somatostatin receptors imaging (SRI) in correlation with multi-phase CT or MRI should be performed, due to its higher sensitivity in comparison to radiological methods [10]. After 5 years in remission $\left.{ }^{68} \mathrm{Ga}\right]$-DOTATATE PET/CT was preformed, due to the suspicion of a recurrence of the neoplasm in lymph nodes. The examination showed extensive metastases in the structures of the heart, bones, muscles, mesentery and intraperitoneal space. Those changes were not revealed in the contrast CT [11]. On the basis of the results stated above, systemic treatment was implemented. The patient was given 12 cycles of long-acting somatostatin analogue $30 \mathrm{mg}$ octreotide IM (Sandostatin LAR), which is the first-line treatment for patients with well-differentiated small intestine NENs [12]. After 12 cycles of treatment, a progression of the disease, an increase in $\mathrm{CgA}$ concentration and a progression

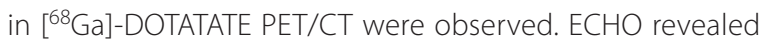
intrapericardial tumours located near the right ventricle and between the right ventricle and the right atrium. Their size was approximately $30 \mathrm{~mm}$ in diameter.

Carcinoid heart disease can occur in up to $50 \%$ patients with carcinoid syndrome and although there were no signs of this syndrome in the patient, intrapericardial tumours turned out to be a life-threatening problem [13]. Such localisation of metastases in the course of NENs is uncommon [14]. The patient was referred to cardiosurgical consultation and died from cardiovascular complications associated with arrhythmia during preparation for surgery.

\section{Conclusion}

The following case of a well-developed small intestine NEN is an example of an oligosymptomatic neoplastic disease. CgA concentration should be checked after the diagnosis and also during each follow-up visit, altogether with performing the abdominal CT [15]. [ ${ }^{68} \mathrm{Ga}$ ]-DOTATATE PET/CT, if performed right after tumour resection, could be of great diagnostic value, even with a low grade tumour with a low chance of metastasis. This examination would allow to determine the success of the surgical treatment and could reveal metastases in lymph nodes or bones - tissues more difficult to examine in CT [1, 15]. A complete resection of the primary site of the neoplasm significantly improves the overall prognosis but does not guarantee full recovery - even after a few years in remission [5]. Regularly performed tests would increase the chances of discovering 
the neoplasm progression, especially with an asymptomatic course of the disease. Due to the atypical metastases in cardiac structures, not corresponding with typical Hedinger syndrome, performing an $\mathrm{ECHO}$ after surgical treatment in the case of no active tumours should be considered as well.

\section{Conflict of interest: none declared}

\section{Agnieszka Żyłka}

M. Sklodowska-Curie National Research Institute of Oncology Department of Endocrine Oncology and Nuclear Medicine

\section{ul. Roentgena 5}

02-781, Warszawa, Poland

e-mail: agnieszka.zylka@pib-nio.pl

Received: 12 Oct 2020

Accepted: 26 Oct 2020

\section{References}

1. Kos-Kudła B, Blicharz-Dorniak J, Strzelczyk J, et al. Consensus Conference, Polish Network of Neuroendocrine Tumours, oraz Pozostali Uczestnicy Konferencji Okragłego Stołu. [Diagnostic and therapeutic guidelines for gastrointestinal neuroendocrine tumors (recommended by the Polish Network of Neuroendocrine Tumors)]. Endokrynol Pol. 2008; 59(1): 41-56, indexed in Pubmed: 18335400.

2. Maggard MA, O'Connell JB, Ko CY. Updated population-based review of carcinoid tumors. Ann Surg. 2004; 240(1): 117-122, doi: 10.1097/01. sla.0000129342.67174.67, indexed in Pubmed: 15213627.

3. Rubin de Celis Ferrari AC, Glasberg J, Riechelmann RP. Carcinoid syndrome: update on the pathophysiology and treatment. Clinics (Sao Paulo). 2018; 73(suppl 1): e490s, doi: 10.6061/clinics/2018/e490s, indexed in Pubmed: 30133565.

4. Davar J, Connolly HM, Caplin ME, et al. Diagnosing and Managing Carcinoid Heart Disease in Patients With Neuroendocrine Tumors: An Expert Statement. J Am Coll Cardiol. 2017; 69(10): 1288-1304, doi: 10.1016/j. jacc.2016.12.030, indexed in Pubmed: 28279296.

5. Bednarczuk T, Bolanowski M, Zemczak A, et al. Neuroendocrine neoplasms of the small intestine and appendix - management guidelines (recommended by the Polish Network of Neuroendocrine Tumours). Endokrynol Pol. 2017; 68(2): 223-236, doi: 10.5603/EP.2017.0018, indexed in Pubmed: 28540974.
6. Niederle B, Pape UF, Costa F, et al. Vienna Consensus Conference participants. ENETS Consensus Guidelines Update for Neuroendocrine Neoplasms of the Jejunum and Ileum. Neuroendocrinology. 2016; 103(2): 125-138, doi: 10.1159/000443170, indexed in Pubmed: 26758972.

7. Neumann H, Fry LC, Neurath MF. Review article on current applications and future concepts of capsule endoscopy. Digestion. 2013; 87(2): 91-99, doi: 10.1159/000345346, indexed in Pubmed: 23306733.

8. Kos-Kudła B, Blicharz-Dorniak J, Handkiewicz-Junak D, et al. Consensus Conference, Polish Network of Neuroendocrine Tumours. Diagnostic and therapeutic guidelines for gastro-entero-pancreatic neuroendocrine neoplasms (recommended by the Polish Network of Neuroendocrine Tumours). Endokrynol Pol. 2013; 64(6): 418-443, doi: 10.5603/ EP.2013.0028, indexed in Pubmed: 24431116.

9. Yao JC, Pavel M, Phan AT, et al. Chromogranin A and neuron-specific enolase as prognostic markers in patients with advanced pNET treated with everolimus. J Clin Endocrinol Metab. 2011; 96(12):3741-3749, doi: 10.1210/jc.2011-0666, indexed in Pubmed: 21994954.

10. Krenning EP, Kwekkeboom DJ, Oei HY, et al. Somatostatin-receptor scintigraphy in gastroenteropancreatic tumors. An overview of European results. Ann NY Acad Sci. 1994; 733:416-424, doi: 10.1111/j.17496632.1994.tb17291.x, indexed in Pubmed: 7978890.

11. Schreiter NF, Bartels AM, Froeling V, et al. Searching for primaries in patients with neuroendocrine tumors (NET) of unknown primary and clinically suspected NET: Evaluation of Ga-68 DOTATOC PET/CT and In-111 DTPA octreotide SPECT/CT. Radiol Oncol. 2014; 48(4): 339-347, doi: 10.2478/raon-2014-0018, indexed in Pubmed: 25435846.

12. Rinke A, Wittenberg $M$, Schade-Brittinger $C$, et al. PROMID Study Group Placebo-Controlled, Double-Blind, Prospective, Randomized Study on the Effect of Octreotide LAR in the Control of Tumor Growth in Patients with Metastatic Neuroendocrine Midgut Tumors (PROMID): Results of Long-Term Survival. Neuroendocrinology. 2017; 104(1): 26-32, doi: 10.1159/000443612, indexed in Pubmed: 26731483.

13. Maroun J, Kocha W, Kvols L, et al. Guidelines for the diagnosis and management of carcinoid tumours. Part 1: the gastrointestinal tract. A statement from a Canadian National Carcinoid Expert Group. Curr Oncol. 2006; 13(2): 67-76, indexed in Pubmed: 17576444.

14. Luis SA, Pellikka PA. Carcinoid heart disease: Diagnosis and management. Best Pract Res Clin Endocrinol Metab. 2016; 30(1): 149-158, doi: 10.1016/j.beem.2015.09.005, indexed in Pubmed: 26971851.

15. Knigge U, Capdevila J, Bartsch DK, et al. Antibes Consensus Conference Participants, Antibes Consensus Conference participants. ENETS Consensus Recommendations for the Standards of Care in Neuroendocrine Neoplasms: Follow-Up and Documentation. Neuroendocrinology. 2017; 105(3): 310-319, doi: 10.1159/000458155, indexed in Pubmed: 28222443. 